\title{
Prevalence and characteristics of chronic Pain in the Chinese community-dwelling elderly: a cross-sectional study
}

\author{
Xiahui $\mathrm{Li}^{1,2,3}$, Wei Zhu ${ }^{2^{*}}$, Jiping $\mathrm{Li}^{\mathrm{i}^{*}} \mathbb{D}$, Chan Huang $^{3}$ and Fan Yang ${ }^{4}$
}

\begin{abstract}
Background: Chronic pain adversely affects health and daily life in the elderly. Gaining insight into chronic pain that affects the community-dwelling elderly is crucial for pain management in China, which possesses the largest elderly population in the world.

Methods: This is a cross-sectional design study that followed the STROBE Guideline. A randomized cluster sampling method was used to recruit participants in the Sichuan Province from Dec 2018 to May 2019. In addition, face-toface interviews were conducted to collect socio-demographic data, characteristics and health-seeking behaviors of chronic pain through a self-designed questionnaire.

Results: A total of 1381 older adults participated in this study. Among these participants, 791 (57.3\%) had chronic pain. Here, prevalence and pain intensity were both found to increase from the 60-69 group to the 70-79 group, which then decreased in the $\geq 80$ group with no significant differences in sex $(p>0.05)$. The most common pain locations were observed in the legs/feet (53.5\%), head (23.6) and abdomen/pelvis (21.1\%). Among the elderly suffering from chronic pain, $29.4 \%$ sought medical help, 59.2\% received medication and $59.7 \%$ adopted non-drug therapy.

Conclusion: Chronic pain is a common health concern in the Chinese community-dwelling elderly, which possesses different characteristics than other countries' populations. Therefore, easier access to medication assistance and provision of scientific guidance for non-drug therapy may serve as satisfactory approaches in improving pain management.
\end{abstract}

Keywords: Chronic pain, The elderly, Community-dwelling, Cross-sectional study

\section{Background}

The International Association for the Study of Pain (IASP) has defined chronic pain as an unpleasant sensory and emotional experience may be associated with tissue damage, which may also be described in term of such damage lasting for over 3 months [1]. With the population aging, a rise in prevalence for chronic and

\footnotetext{
*Correspondence: 310898831@qq.com; jp-li@163.com

${ }^{2}$ West China Hospital, Sichuan University, Chengdu City 610041, Sichuan Province, China

Full list of author information is available at the end of the article
}

degenerated diseases is inevitable, leading to a high incidence of chronic pain in the elderly [2,3]. Previous studies have investigated the incidence of chronic pain in the elderly, showing a prevalence ranging from 43.8 to $55.2 \%$ in elderly population residing in the east [4-7] while 40 to $66 \%$ prevalent among those in the west [8, 9]. Moreover, the most common sites of pain in older people are the back, leg, knee or hip, and 'other' joints (such as joints of fingers, wrists and toes) in the most developed countries [10].

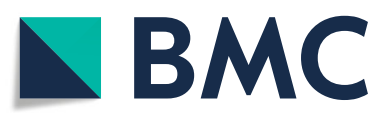

(c) The Author(s). 2021 Open Access This article is licensed under a Creative Commons Attribution 4.0 International License, which permits use, sharing, adaptation, distribution and reproduction in any medium or format, as long as you give appropriate credit to the original author(s) and the source, provide a link to the Creative Commons licence, and indicate if changes were made. The images or other third party material in this article are included in the article's Creative Commons licence, unless indicated otherwise in a credit line to the material. If material is not included in the article's Creative Commons licence and your intended use is not permitted by statutory regulation or exceeds the permitted use, you will need to obtain permission directly from the copyright holder. To view a copy of this licence, visit http://creativecommons.org/licenses/by/4.0/. The Creative Commons Public Domain Dedication waiver (http://creativecommons.org/publicdomain/zero/1.0/) applies to the data made available in this article, unless otherwise stated in a credit line to the data. 
Chronic pain significantly impairs the health status and daily life of the elderly. Previous studies have found that chronic pain impairs the activities of daily living $[11,12]$, dignity [13], sleep quality [14] and quality of life [15]. Chronic pain was also reported to cause social isolation, fatigue and depression in the elderly $[8,16]$. Moreover, chronic pain can increase the utilization of medical resources of society as well as the healthcare costs of individuals $[15,17]$. Despite a series of studies on chronic pain in the elderly, the prevalence and impacts of chronic pain in the elderly remain underestimated. Pain is always a recognized feature of old age to both physicians and caregivers [18]. In terms of the elderly, nociception may change with aging, and the affected elderly become accustomed to living with chronic pain, causing them not to report their pain or seek medical attention [19]. Some elderly populations suffering from moderate to severe pain reported no pain management $[20,21]$, and some have concerned about using analgesics [22], resulting in misuse of potentially helpful treatments [23]. Fortunately, one-third of older peoples could use both pharmacologic strategies and nonpharmacologic strategies to manage pain. The most prevalent nonpharmacologic strategies among them were exercise, nutritional supplements, ointments, heat and massage [20]. Nevertheless, there were substantial ethnic disparities reported in pain prevalence, conditions and coping strategies [24]. It is necessary to gain insight into the prevalence and pain-related health-seeking behaviors in the elderly according to different cultural and economic backgrounds.

Chronic pain is also a major health problem in China as the country possesses the largest elderly population in the world. According to the National Bureau of Statistics of China, the proportion of people aged 60 years and above had reached $16 \%$ in 2015 [25]. Thus, researchers have conducted studies to investigate the prevalence of chronic pain in the Chinese elderly population. Xue, $\mathrm{Chu}$ [26] investigated the prevalence of chronic pain in the elderly in those aged 80 years and above in four provinces in China, and found that $76.4 \%$ of participants suffered from chronic pain. Moreover, Wang, Xu [27] conducted a survey in elderly inpatients and reported that $55.5 \%$ of elderly inpatients had chronic pain. Accordingly, studies focusing on community-dwelling elderly mainly reported the prevalence of chronic pain rather than on characteristics like interference with daily life, health-seeking behaviors or conditions of medication use among the corresponding elderly $[6,28]$. The aforementioned studies focused on specific subpopulations or prevalence of chronic pain that had limited insights into chronic pain. Therefore, getting a deeper insight into chronic pain, including its prevalence, characteristics, pain-related health-seeking behaviors in community-dwelling elderly are crucial for policymaking and chronic pain management.

\section{Objectives}

This study aimed to investigate the prevalence, characteristics and pain-related health-seeking behaviors in the Chinese community-dwelling elderly.

\section{Methods}

Study design

This is a cross-sectional study that followed the Strengthening the Reporting of Observational Studies in Epidemiology (STROBE) statement.

\section{Setting}

This study was conducted in the Sichuan Province in west China from Dec 2018 to May 2019, where people aged 60 years old or above has exceeded $9 \%$ of the population.

\section{Participants}

The participants in this study were recruited in two stages. First, from 21 cities/autonomous prefectures in Sichuan Province, seven cities/autonomous prefectures were selected according to their socioeconomic status (Chengdu City, Luzhou City, Zigong City, Neijiang City, Nanchong City, Ganzi Autonomous Prefecture and Mianyang City). Second, a random cluster sampling method was used to recruit participants from 7 communities from the selected cities/autonomous prefectures. The inclusion criteria were: participants who were older than 60-year-old and those who agree to participate in the study. The exclusion criteria were: difficulties in communication and psychological diseases. The expected prevalence of chronic pain was set as $49.8 \%$, according to a recent study in China [6]. A sample size of 1152 was calculated using the formula: $Z_{\alpha / 2}^{2} p(1-p) D E F F / d^{2}$, in which $\alpha=0.05, p=0.498, \mathrm{DEFF}=3, d=0.05$ [29]. In order to compensate for potential mistakes and missing values (10\%), the final sample size was 1267 participants. This study was approved by the Ethic Committee of Chengdu University.

\section{Data collection}

Seven trained research assistants responsible for each community completed the face-to-face interviews. First, the research assistants explained the purpose and procedure of the study and obtained the participants' written informed consent. Then, the research assistants conducted an investigation for about $30 \mathrm{~min}$ in a quiet room in the community hospital by the questionnaire developed for this study (Additional file 1) to collect socio-demographic data (age, sex, education level, living 
status, marital status, monthly income and comorbidities), characteristics of chronic pain (pain location, intensity, interference with daily life and precipitating factors), health-seeking behaviors (usage of medication and non-drug therapy) and self-rated health. The completeness of the collected data was checked by the authors in charge of data collection after research assistants completed the interviews.

\section{Measurements \\ Chronic pain}

Pain lasting $\geq 3$ months was defined as chronic pain following the IASP classification. Therefore, in this study, chronic pain was measured by two questions: (1) "Did you have a pain experience?"; (2) "If yes, how long did you get the pain?". Moreover, if participants experienced chronic pain, the pain location (eight locations based on a study from Mccarthy, Bigal [30]), precipitating factors of pain were also questioned and recorded. Additionally, the use of medication and non-drug therapy was assessed by three main questions followed by specific questions: (1) When you have pain, what do you usually do? (2) Do you take any medicine to relieve the pain? (3) Have you taken any other measures to relieve the pain besides medication?

\section{Pain intensity}

Brief Pain Inventory (BPI) [31] scale was used to evaluate pain intensity. This subscale is recommended for elderly pain assessment as it evaluates overall pain rather than site-specific pain [32]. Participants were asked to rate the severity of pain in the last week based on four aspects (worst pain, least pain, pain on average and pain right now), according to an 11-point numeric rating scale. The " 0 " indicated "no pain" while "10" indicated "severe or excruciating pain you cannot imagine". A higher score signified more severe pain. This subscale has good internal consistency with a Cronbach's alpha coefficient of 0.84 [33].

\section{Interference of pain with daily life}

In this study, interference of pain with daily life was evaluated using a single pain interference subscale extracted from BPI. This pain interference subscale consisted of seven items, including general activity, mood, walk, working, relationship, sleep and enjoyment. Participants were asked to rate the degree of interference with daily life using an 11-point numeric rating scale, with " 0 " indicating "no interference" and "10" indicating "interference cannot tolerate". The pain interference subscale also had good internal consistency with a Cronbach's alpha coefficient of 0.94 [33].

\section{Self-rated health}

The self-rated health was evaluated by the question: "How satisfied you are with your health?" with the answers ranging from "very bad", "bad", "general", "good" and "very good" [34].

\section{Data analysis}

Chi-square test was used to compare the differences between socio-demographic groups of participants with or without chronic pain, the characteristics of chronic pain according to age and sex, and the health seeking behaviors and medication use of participants in different residence location.

Binary logistic regression was used to analyze the influence of socio-demographic factors on the presence of chronic pain.

Mann-Whitney $U$ test was used to compare the characteristics of chronic pain according to age and sex while Student-Newman-Keuls test and Bonferroni correction method were used to compare groups in pairs where three or more groups were compared.

ANOVA and Kruskal-Wallis $\mathrm{H}$ test was used to compare the impact of chronic pain on daily life and selfrated health according to age.

All data analyses were performed using IBM SPSS Statistics Version 23.0 for Windows 7 (Armonk, NY: IBM Corp).

\section{Results \\ Socio-demographic data and prevalence of chronic pain of participants}

A total of 1450 elderly individuals satisfied the inclusion criteria, and 1403 of them agreed to participate in this study. Finally, 22 did not complete the interview, and 1381 participants were finally enrolled. The participants mainly consisted of females $(55.3 \%)$ and elderly aged from 60 to 69 years old (45.1\%). The elderly participants with no education were $26.1 \%$ of all participants. Most participants were located in urban areas (71.7\%) and suffered from comorbidities (92.5\%). Over $10 \%$ of participants had a monthly disposable personal income of under 275 RMB. Table 1 shows the detailed data of participants with and without chronic pain. Among all samples, 791 participants suffered from chronic pain (57.3\%). Participants living in rural areas, having lower monthly income and comorbidities were more likely to have chronic pain $(p<0.01)$. However, Table 2 shows the impact of residence location on chronic pain may be due to interaction of some other factors not covered in this study, as it was not statistically significant in the binary logistic regression models. 
Table 1 Socio-demographic data of participants with or without chronic pain $(N=1381)$

\begin{tabular}{|c|c|c|c|c|c|}
\hline Characteristics & Total $(N=1381)$ & Chronic pain $(N=791)$ & No chronic pain $(N=590)$ & $x^{2} / Z$ & $P$ value \\
\hline \multicolumn{6}{|l|}{ Sex } \\
\hline Male & $617(44.7)$ & $339(42.9)$ & $278(47.1)$ & 2.483 & 0.115 \\
\hline Female & $764(55.3)$ & $452(57.1)$ & $319(52.9)$ & & \\
\hline \multicolumn{6}{|l|}{ Age } \\
\hline $60-69$ & $623(45.1)$ & $357(45.1)$ & $266(45.1)$ & -0.420 & 0.675 \\
\hline $70-79$ & $541(39.2)$ & $302(38.2)$ & $239(40.5)$ & & \\
\hline$\geq 80$ & $217(15.7)$ & $132(16.7)$ & $85(14.4)$ & & \\
\hline \multicolumn{6}{|l|}{ Marital status } \\
\hline Married & $1023(74.1)$ & $594(75.1)$ & $429(72.1)$ & 3.104 & 0.212 \\
\hline Divorced/Widowed & $256(18.5)$ & 147 (18.6) & 109 (18.5) & & \\
\hline Unmarried & $102(7.4)$ & $50(6.3)$ & $52(8.8)$ & & \\
\hline \multicolumn{6}{|l|}{ Education level } \\
\hline Illiteracy & $360(26.1)$ & $225(28.4)$ & $135(22.9)$ & 5.502 & 0.064 \\
\hline Primary & $494(35.8)$ & $276(34.9)$ & $218(36.9)$ & & \\
\hline Secondary or above & $527(38.1)$ & $290(36.7)$ & $237(40.2)$ & & \\
\hline \multicolumn{6}{|l|}{ Residence location } \\
\hline Urban area & $990(71.7)$ & $527(66.6)$ & $463(78.5)$ & 23.380 & $<0.001$ \\
\hline Rural area & $391(28.3)$ & $264(33.4)$ & $127(21.5)$ & & \\
\hline \multicolumn{6}{|l|}{ Living alone } \\
\hline Yes & $129(9.3)$ & $69(8.7)$ & $60(10.2)$ & 0.835 & 0.361 \\
\hline No & $1252(90.7)$ & $722(91.3)$ & $530(89.8)$ & & \\
\hline \multicolumn{6}{|l|}{ Monthly DPI (RMB) } \\
\hline$<275$ & 188 (13.6) & 139 (17.6) & $49(8.3)$ & -6.691 & $<0.001$ \\
\hline $275-1700$ & $449(32.5)$ & $283(35.8)$ & $166(28.1)$ & & \\
\hline$\geq 1700$ & 744 (53.9) & 369 (46.6) & 375 (63.6) & & \\
\hline \multicolumn{6}{|l|}{ Comorbidity } \\
\hline Yes & $1278(92.5)$ & $765(96.7)$ & $513(86.9)$ & 46.676 & $<0.001$ \\
\hline No & $103(7.5)-$ & $26(3.3)$ & $77(13.1)$ & & \\
\hline
\end{tabular}

DPI disposable personal income

Table 2 The influence of socio-demographic factors on the presence of chronic pain $(N=1381)$

\begin{tabular}{llllll}
\hline & B & S.E. & Wald & P & OR (OR95\%Cl) \\
\hline $\begin{array}{llll}\text { Residence location } \\
\text { Monthly DPI (RMB) }\end{array}$ & 0.217 & 0.146 & 2.210 & 0.137 & $1.24(0.933,1.655)$ \\
$275-1700$ VS. $<275$ & & & & & \\
$\quad \geq 1700$ VS. $<275$ & 0.894 & 0.201 & 19.692 & $0.000^{* *}$ & $2.44(1.647,3.628)$ \\
Comorbidity & 0.411 & 0.135 & 9.347 & $0.002^{* *}$ & $1.51(1.159,1.965)$ \\
Constant & 1.386 & 0.237 & 34.200 & $0.000^{* *}$ & $4.00(2.513,6.364)$ \\
\hline
\end{tabular}


Table 3 Characteristics of chronic pain according to age and sex $(N=791)$

\begin{tabular}{|c|c|c|c|c|c|c|}
\hline Characteristics & Total & Male $(N=339)$ & Female $(N=452)$ & $\begin{array}{l}60-69 \\
(N=357)\end{array}$ & $\begin{array}{l}70-79 \\
(N=302)\end{array}$ & $\begin{array}{l}\geq 80 \\
(N=132)\end{array}$ \\
\hline \multicolumn{7}{|l|}{ Pain intensity } \\
\hline Worst pain & $5.6 \pm 2.2$ & $5.6 \pm 2.2$ & $5.5 \pm 2.2$ & $5.2 \pm 2.2$ & $6.0 \pm 2.2$ & $5.6 \pm 2.3^{* *, a}$ \\
\hline Least pain & $2.2 \pm 1.8$ & $2.2 \pm 1.9$ & $2.2 \pm 1.7$ & $1.9 \pm 1.6$ & $2.5 \pm 2.0$ & $2.3 \pm 1.8^{* *, a}$ \\
\hline Pain on average & $3.7 \pm 1.7$ & $3.7 \pm 1.8$ & $3.6 \pm 1.7$ & $3.3 \pm 1.5$ & $4.2 \pm 1.9$ & $3.9 \pm 1.7^{* *, a}$ \\
\hline Pain right now & $2.9 \pm 2.0$ & $2.9 \pm 2.1$ & $3.0 \pm 1.9$ & $2.7 \pm 1.8$ & $3.2 \pm 2.1$ & $2.9 \pm 2.0^{* *, a}$ \\
\hline \multicolumn{7}{|l|}{ Pain location } \\
\hline Head & 187 (23.6) & $85(25.1)$ & $102(22.6)$ & $91(25.5)$ & $72(23.8)$ & $24(18.2)$ \\
\hline Face & $26(3.3)$ & $15(4.4)$ & $11(2.4)$ & $8(2.2)$ & $12(4.0)$ & $6(4.5)$ \\
\hline Neck/shoulder & $151(19.1)$ & 49 (14.5) & $102(22.6)^{* *}$ & $80(22.4)$ & 59 (19.5) & $12(9.1)^{* *, b}$ \\
\hline Back & $114(14.4)$ & $42(12.4)$ & $72(15.9)$ & 42 (11.8) & $49(16.2)$ & $23(17.4)$ \\
\hline Arms/hands & 149 (18.8) & $55(16.2)$ & $94(20.8)$ & 71 (19.9) & $63(20.9)$ & 15 (11.4) \\
\hline Legs/feet & $431(53.5)$ & $165(48.7)$ & $266(58.8)^{* *}$ & 177 (49.6) & $182(60.3)$ & $72(54.5)^{* *, b}$ \\
\hline Chest & $124(15.7)$ & $62(18.3)$ & $62(13.7)$ & $57(16.0)$ & $45(14.9)$ & $22(16.7)$ \\
\hline Abdomen/pelvis & $167(21.1)$ & $82(24.2)$ & 85 (18.8) & $80(22.4)$ & $62(20.5)$ & 25 (18.9) \\
\hline
\end{tabular}

${ }^{\mathrm{a}}$ Student-Newman-Keuls; ${ }^{\mathrm{b}}$ Bonferroni correction; ${ }^{* * *} p<0.01 ;{ }^{*} p<0.05$;

\section{Characteristics of chronic pain}

Table 3 displays the pain intensity and pain location of participants with chronic pain. There were no significant differences in pain intensity between male and female participants regardless of worst pain, least pain, pain on average and pain right now $(p>0.05)$. Participants in the 70-79 age group had significantly higher worst pain compared to $60-69$ and $\geq 80$ age groups $(p<0.05)$. Participants in the 60-69 age group had significantly lower least pain and pain on average compared to the other two groups $(p<0.05)$. Participants in the $60-69$ age group had significantly lower pain right now than the 70-79 group $(p<0.05)$. The most common pain locations were found to be in the legs/feet (53.3\%), head (23.6\%) and abdomen/pelvis (21.1\%). Females had a significantly higher incidence of neck/shoulder and legs/ feet pain than males $(22.6 \%$ vs $14.5 \%, p<0.01 ; 58.8 \%$ vs $48.7 \%, p<0.01)$. Participants in the $\geq 80$ age group significantly reported less neck/shoulder pain than the 60 69 and $70-79$ age groups $(p<0.05)$. Furthermore, participants in the $70-70$ age group had significantly more legs/feet pain $(p<0.05)$.

Impact of chronic pain on daily and self-rated health

Table 4 illustrates interference with the daily life of chronic pain and self-rated health in participants with

Table 4 Impact of chronic pain on daily life and self-rated health according to age

\begin{tabular}{|c|c|c|c|c|c|c|}
\hline Items & Total & $60-69(N=357)$ & $70-79(N=302)$ & $\geq 80(N=132)$ & $F / H$ & $P$ value \\
\hline \multicolumn{7}{|l|}{ Daily activity } \\
\hline General activity & $3.7 \pm 2.4$ & $3.3 \pm 2.2$ & $4.2 \pm 2.5$ & $3.9 \pm 2.5$ & $25.793^{\mathrm{a}}$ & $<0.001$ \\
\hline Mood & $3.5 \pm 2.4$ & $3.0 \pm 2.1$ & $3.9 \pm 2.5$ & $3.6 \pm 2.3$ & $26.907^{\mathrm{a}}$ & $<0.001$ \\
\hline Walk & $3.6 \pm 2.6$ & $3.0 \pm 2.3$ & $4.1 \pm 2.7$ & $4.3 \pm 2.8$ & $40.149^{a}$ & $<0.001$ \\
\hline Working & $1.4 \pm 2.2$ & $1.2 \pm 1.9$ & $1.8 \pm 2.5$ & $1.2 \pm 2.1$ & $9.014^{\mathrm{a}}$ & 0.011 \\
\hline Relationships & $2.7 \pm 2.3$ & $2.3 \pm 2.1$ & $3.1 \pm 2.6$ & $2.9 \pm 2.4$ & $14.579^{\mathrm{a}}$ & 0.001 \\
\hline Sleep & $3.9 \pm 2.6$ & $3.6 \pm 2.5$ & $4.3 \pm 2.7$ & $4.1 \pm 2.7$ & $6.919^{a}$ & 0.001 \\
\hline Enjoy & $3.0 \pm 2.4$ & $2.6 \pm 2.1$ & $3.4 \pm 2.5$ & $3.0 \pm 2.4$ & $15.371^{\mathrm{a}}$ & 0.001 \\
\hline \multicolumn{7}{|l|}{ Self-rated heath } \\
\hline Very bad & $33(4.2)$ & $11(3.1)$ & $13(4.3)$ & $9(6.8)$ & 17.265 & $<0.001$ \\
\hline Bad & $201(25.4)$ & $67(18.8)$ & $90(29.8)$ & $44(33.3)$ & & \\
\hline General & 331 (41.8) & $161(45.1)$ & $123(40.7)$ & 47 (35.6) & & \\
\hline Good & 91 (11.5) & $48(13.4)$ & $28(9.3)$ & 15 (11.4) & & \\
\hline Very good & 135 (17.1) & 70 (19.6) & 48 (15.9) & 17 (12.9) & & \\
\hline
\end{tabular}

${ }^{a}$ : Student-Newman-Keuls 
chronic pain. The most affected aspects of daily life were sleep $(3.9 \pm 2.6)$, general activity $(3.7 \pm 2.4)$ and walking $(3.6 \pm 2.6)$. Participants in the $60-69$ age group had significantly lower general activity, mood, walking, relationship and sleep scores than the other two groups $(p<$ 0.05). Moreover, participants in the 70-79 age group had significantly higher working scores compared to the other two groups $(p<0.05)$. Participants in the 70-79 age group had significantly higher enjoy scores compared to the 60-69 age group $(p<0.05)$. A total of 234 (29.6\%) participants reported bad health conditions. Additionally, participants with bad health were found to increase with aging.

\section{Excepted precipitating factors for chronic pain}

The excepted precipitating factors for chronic pain are displayed in Table 5 . Up to $35.5 \%$ of chronic pain was precipitated by chills, while $32.1 \%$ of chronic pain was precipitated by excessive fatigue. Humidity was also a common precipitating factor for chronic pain (19.7\%). Moreover, over one-third (37.3\%) of chronic pain was precipitated by unspecific factors.

\section{Health seeking behaviors of participants with chronic pain}

Table 6 displays the health-seeking behaviors of participants with chronic pain. $29.4 \%$ of participants had asked for medical help, and mostly (44.4\%) chose to handle the pain themselves. Moreover, up to $40.8 \%$ of participants with chronic pain did not receive medication. The medication use rate in rural areas was significantly higher than in urban areas $(p<0.001)$. The most popular nondrug therapies adopted were massages (21.4\%), hot/cold compresses (16.4\%) and acupuncture (13.8\%). Those living in urban areas significantly intended to take acupuncture, cupping therapy, electrical stimulation and massage to cope with chronic pain than the participants in a rural area.

\section{Discussion}

In this cross-sectional study, we learned the basic characteristics of chronic pain in the elderly community in Sichuan Province. 57.3\% of community-dwelling older adults residing in west China were found to have

Table 5 Excepted precipitating factors of chronic pain $(N=791)$

\begin{tabular}{lll}
\hline Factors & Frequency & Percentage \\
\hline Excessive fatigue & 254 & 32.1 \\
Chill & 281 & 35.5 \\
Humidity & 156 & 19.7 \\
Life event & 39 & 4.9 \\
Bad mood & 44 & 5.6 \\
Unspecific factors & 295 & 37.3 \\
\hline
\end{tabular}

chronic pain, precipitated mainly by chills and excessive fatigue. In addition, elderly individuals aged 60-69 years were more likely to have mild pain. The first three common pain locations were observed in the legs/feet, head and abdomen/pelvis. The most affected aspect of daily life due to chronic pain was sleep. Moreover, elderly aged between 60 and 69 years old were less affected by chronic pain according to general activity, mood, walk, relationship and sleep. Nearly half of those with chronic pain did not use medication and over half adopted nondrug therapy.

Surprisingly, the prevalence of chronic pain in this study was significantly higher than previous studies conducted by Li, Chen [6] and Si, Wang [28], which respectively reported that the prevalence of chronic pain in Chinese community-dwelling elderly were 49.8 and $41.1 \%$. The reasons why the prevalence was higher in this study may be the gap of economic and medical resources between East China and West China. Li, Chen [6] and Si, Wang [28] both recruited participants from East China whose economic and medical resources are much better than that of west China, and economic status was previously observed to influence the incidence of chronic pain [35]. Moreover, Si, Wang [28] only investigated samples from the capital city owning the best economic and medical resources in Shandong Province, leading to a lower incidence of chronic pain.

In terms of sex, most previous studies revealed that females were more likely to have chronic pain $[8,9,28$, 36], which was inconsistent with this study. It is generally believed that females are more sensitive to pain due to their unique biological or psychological mechanisms [37, 38]. Moreover, females usually live longer than males; hence, the difference increases with aging. In this respect, this study did not find any differences in the prevalence of chronic pain based on sex, suggesting that regional and cultural differences may need to be considered when the relationship between sex and chronic pain be examined $[39,40]$.

The current study results showed that pain intensity did not increase with aging and decreased after 80 years of age. However, other studies have also found a decrease in pain prevalence with age up to 85 years [41, 42], which may be related to the decreased perception of pain caused by sensory dysfunction in people over 80 years old.

This study found that elderly living with lower monthly incomes had a higher prevalence of chronic pain, confirmed by other studies [4, 43, 44]. Socioeconomic factors have been associated with worse health outcomes, for those living in poverty, low incomes haunt each financial decision, and many are unable to consistently afford prescribed interventions such as medications and ongoing visits to health care providers to manage 
Table 6 Health seeking behaviors and medication use of participants with chronic pain $(N=791)$

\begin{tabular}{|c|c|c|c|c|c|}
\hline \multirow[t]{2}{*}{ Items } & \multirow[t]{2}{*}{ Total } & \multicolumn{2}{|c|}{ Residence location } & \multirow[t]{2}{*}{$x^{2}$} & \multirow{2}{*}{$\begin{array}{l}P \\
\text { value }\end{array}$} \\
\hline & & Urban $(N=527)$ & Rural $(N=264)$ & & \\
\hline \multicolumn{6}{|l|}{ Health seeking } \\
\hline Enduring & $207(26.2)$ & $138(26.2)$ & $69(26.1)$ & 1.485 & 0.467 \\
\hline Handling by oneself & $351(44.4)$ & $227(43.1)$ & $124(47.0)$ & & \\
\hline Seeking for medical help & $233(29.4)$ & $162(30.7)$ & $71(26.9)$ & & \\
\hline \multicolumn{6}{|l|}{ Medication use } \\
\hline Yes & $468(59.2)$ & $281(53.3)$ & $187(70.8)$ & 22.308 & $<0.001$ \\
\hline No & $323(40.8)$ & $246(46.7)$ & $77(29.2)$ & & \\
\hline \multicolumn{6}{|l|}{ Non-drug therapy adopted } \\
\hline No & $319(40.3)$ & $200(38.0)$ & $119(45.1)$ & 3.711 & 0.054 \\
\hline Yes & $472(59.7)$ & $327(62.0)$ & $145(54.9)$ & & \\
\hline Acupuncture & $109(13.8)$ & $84(15.9)$ & $25(9.5)$ & 6.196 & 0.013 \\
\hline Cupping therapy & $71(9.0)$ & $55(10.4)$ & $16(6.1)$ & 4.122 & 0.042 \\
\hline Electrical stimulation & $48(6.1)$ & $46(8.7)$ & $2(0.8)$ & 19.606 & $<0.001$ \\
\hline Massage & $169(21.4)$ & $133(25.2)$ & 36 (13.6) & 14.089 & $<0.001$ \\
\hline Distraction & $43(5.4)$ & $33(6.3)$ & $10(3.8)$ & 2.094 & 0.148 \\
\hline Hot/cold compress & $130(16.4)$ & $80(15.1)$ & $50(18.9)$ & 1.810 & 0.179 \\
\hline Others & $31(3.9)$ & $25(4.7)$ & $6(2.3)$ & 2.852 & 0.091 \\
\hline
\end{tabular}

their health [45]. Therefore, it is important for policymakers to pay more attention to the elderly population.

In our study, significant relationship between the prevalence of chronic pain and education level was not observed, which was inconsistent with previous studies that reported a lower level of education indicated a higher incidence of chronic pain $[28,36]$. They believed that patients with low education level might delay the visit or treatment due to insufficient health awareness, who fail to treat chronic pain-related illnesses early [46]. Therefore, the results of this study may imply that older people with higher education in western China still lack sufficient health awareness. However, another factor was that a higher prevalence of chronic pain was observed in elderly with a lower level of education, which may be associated with the wrong perception that chronic pain is due to low education levels rather than low socioeconomic status [36].

This study found that elderly living in rural areas had a lower prevalence of chronic pain, but the impact of residence location on chronic pain may be due to interaction of some other factors, which might be lifestyle, economic burden and health seeking behavior. The economic conditions in urban areas are better than those in rural areas in western China, however earlier findings have shown that older people living in poorer neighborhoods are more likely to suffer from chronic pain [45, 47]. The reason for this paradoxical result in this study might be because older people living in cities have a modern way of life, which is not healthier and leading to increased risk for kinds of chronic disease, including chronic pain [48]. Studies have shown that the health care costs was higher in developed cities [49], which may lead to the lack of treatment for pain due to the heavy economic burden of disease treatment in some elderly people. In this study it was also found that the medication use rate in rural areas was higher than in urban areas among older adults with chronic pain.

In this study, the most common pain locations were found in the legs/feet, head and abdomen/pelvis. However, the ranking of the reported pain locations was observed to vary greatly across different studies. For example, Korean elderly individuals most frequently reported back pain [50]. Moreover, the elderly from the UK and Spain mostly reported lower limb pain [51, 52], while the Polish elderly mainly suffered from pain in their lumbar regions [18].

In daily life activities, chronic pain was found to interfere mainly in sleep, general activity and walk in this study. Si, Wang [28] also found a strong association between sleep disturbance, decreased physical activity and chronic pain in the elderly, which may be due to functional changes in the nervous system, where pain and sleep are both modulated due to long-term chronic pain [53]. It was previously found to be necessary to focus on the sleep quality of elderly with chronic pain. In terms of activity, fear of pain avoid them from exercise, daily selfcare, and even any move [54]., which could endanger their independence and quality of life, with reduced levels of fitness and function leading to increased levels 
of disability [10]. Therefore, it is important for health care providers to educate older people to maintain and increase physical activities.

Unsurprisingly, only $29.4 \%$ of participants in this study actively sought medical help, and over $40 \%$ did not receive medication. The corresponding result was similar to that of Liberman, Freud [55], who reported that only $41.1 \%$ of the elderly used medication. However, over half of participants in this study adopted non-drug therapies such as massages, hot/cold compresses, and acupuncture, which may have reduced the medication use rate, especially in elderly living in urban areas. Thus, providing easy access to medication assistance and scientific non-drug therapy guidance to the elderly suffering from chronic pain may benefit and improve pain management.

There are some limitations to this study. First, this was a cross-sectional study conducted in west China, where economic and medical statuses differed from other parts of China. Thus, the representativeness of the sample was limited because economic and medical resources influenced the prevalence and characteristics of chronic pain. Second, precipitating factors and medication use for chronic pain may vary according to the different biological or pathological characteristics of chronic pain. In this study, we could not verify these variations; hence, researchers should be cautious in generalizing the results of the precipitating factors, pain locations and medication use conditions.

\section{Conclusion}

Chronic pain is a common health concern in the Chinese community-dwelling elderly with a prevalence of $57.3 \%$. The prevalence and intensity of chronic pain did not increase with aging and showed no differences with respect to sex. Pain in the legs/feet was the most reported pain location in both males and females. Furthermore, easier access to medication assistance and scientific guidance for non-drug therapy may be helpful in improving pain management in the elderly population.

\section{Abbreviations \\ IASP: International Association for the Study of Pain; STROBE: Strengthening the Reporting of Observational Studies in Epidemiology; BPI: Brief Pain Inventory; RMB: Renminbi; DPI: Disposable personal income; UK: United Kingdom}

\section{Supplementary Information}

The online version contains supplementary material available at https://doi. org/10.1186/s12877-021-02432-2

\section{Additional file 1}

\section{Acknowledgements}

We would like to thank all the participants in the study for taking part in the study.

\section{Authors' contributions}

$J \mathrm{~L}$ and $\mathrm{XL}$ developed the proposal and designed the protocol, WZ were involved in revising the proposal and design. $\mathrm{XL} W Z$ and $\mathrm{CH}$ were involved in data collection, and analysis. XL and WZ drafted the manuscript. JL and FY revised the analysis and helped in the preparation of the manuscript. All the authors have read and approved the final version of the manuscript.

Funding

Not applicable.

Availability of data and materials

The data that supports the findings in this study can be made available through contacting the corresponding author under reasonable request.

\section{Declarations}

Ethics approval and consent to participate

The study procedure was approved by the the Ethnic Committee of Chengdu University. Written informed consent was obtained from all participants before they took part in the study, and all participants were informed that they have the right not to participate in the study. All information obtained in the study was kept confidential.

Consent for publication

Not applicable.

\section{Competing interests}

The authors declare that they have no competing interests.

\section{Author details}

'West China School of Nursing, Sichuan University, Chengdu City, Sichuan Province, China. ${ }^{2}$ West China Hospital, Sichuan University, Chengdu City 610041, Sichuan Province, China. ${ }^{3}$ School of Nursing, Chengdu University, Chengdu City, Sichuan Province, China. ${ }^{4}$ West China Second Hospital, Sichuan University, Chengdu City, Sichuan Province, China.

Received: 13 December 2020 Accepted: 20 July 2021

Published online: 07 October 2021

\section{References}

1. IASP. Classification of chronic pain: Descriptions of chronic pain syndromes and definitions of pain terms. Pain Suppl. 1986;3:S1-226.

2. Santos $A M B$, et al. Prevalence of fibromyalgia and chronic widespread pain in community-dwelling elderly subjects living in Sao Paulo, Brazil. Maturitas. 2010;67(3):251-5. https://doi.org/10.1016/j.maturitas.2010.07.006.

3. Pereira $\mathrm{L}$, et al. Prevalence and intensity of chronic pain and self-perceived health among elderly people: a population-based study. Revista LatinoAmericana de Enfermagem. 2014;22(4):662-9. https://doi.org/10.1590/01 04-1169.3591.2465

4. Nakai $Y$, Makizako H, Kiyama R, Tomioka K, Taniguchi $Y$, Kubozono T, et al. Association between chronic Pain and physical frailty in communitydwelling older adults. Int J Environ Res Public Health. 2019;17(1):1330. https://doi.org/10.3390/ijerph17010175.

5. Kirubakaran S, Dongre AR. Chronic musculoskeletal pain among elderly in rural Tamil Nadu: mixed-method study. J Fam Med Prim Care. 2019:8(1):77_ 85. https://doi.org/10.4103/jfmpc.jfmpc_290_17.

6. Li J, Chen J, Qin Q, Zhao D, Dong B, Ren Q, et al. Chronic pain and its association with obesity among older adults in China. Arch Gerontol Geriatr. 2018:76:12-8. https://doi.org/10.1016/j.archger.2018.01.009.

7. Inoue $S$, Kobayashi F, Nishihara M, Arai YCP, Ikemoto T, Kawai T, et al. Chronic pain in the japanese community_-prevalence, characteristics and impact on quality of life. PLoS One. 2015;10(6). https://doi.org/10.1371/ journal.pone.0129262.

8. Rapopylkko S, Haanpaa M, Liira H. Chronic pain among communitydwelling elderly: a population-based clinical study. Scand J Prim Health Care. 2016;34(2):159-64. https://doi.org/10.3109/02813432.2016.1160628.

9. Miro J, et al. Pain in older adults: a prevalence study in the Mediterranean region of Catalonia. Eur J Pain. 2007;11(1):83-92. https://doi.org/10.1016/j. ejpain.2006.01.001.

10. Abdulla A, et al. Guidance on the management of pain in older people. Age Ageing. 2013;42(Suppl 1):i1-57. 
11. Eggermont LHP, Penninx BWJH, Jones RN, Leveille SG. Depressive symptoms, chronic Pain, and falls in older community-dwelling adults: the MOBILIZE Boston study. J Am Geriatr Soc. 2012;60(2):230-7. https://doi.org/1 0.1111/j.1532-5415.2011.03829.x.

12. Buchman AS, Shah RC, Leurgans SE, Boyle PA, Wilson RS, Bennett DA. Musculoskeletal pain and incident disability in community-dwelling older adults. Arthritis Care Res. 2010;62(9):1287-93. https://doi.org/10.1002/acr.202 00 .

13. Herr K, Garand L. Assessment and measurement of pain in older adults. Clin Geriatr Med. 2001;17(3):457-78. https://doi.org/10.1016/S07490690(05)70080-X.

14. Miu DKY, Chan KC. Under-detection of pain in elderly nursing home residents with moderate to severe dementia. J Clin Gerontol Geriatr. 2013; 5(1):23-7. https://doi.org/10.1016/j.jcgg.2013.09.001.

15. Bernfort L, Gerdle B, Rahmqvist M, Husberg M, Levin LÅ. Severity of chronic pain in an elderly population in Sweden--impact on costs and quality of life. Pain. 2015;156(3):521-7. https://doi.org/10.1097/01.j.pain.0000460336.31600. 01.

16. Ohayon MM. Specific characteristics of the pain/depression association in the general population. J Clin Psychiatry. 2004;65(Suppl 12):5-9.

17. Pizzi LT, Carter CT, Howell JB, Vallow SM, Crawford AG, Frank ED. Work loss, healthcare utilization, and costs among US employees with chronic Pain Dis Manag Health Outcomes. 2005;13(3):201-8. https://doi.org/10.2165/0011 5677-200513030-00005.

18. Elzbieta KS, et al. Prevalence of chronic pain in the elderly polish population - results of the PolSenior study. Arch Med Ence Ams. 2017;13:1197-206.

19. Sofaer B, Moore AP, Holloway I, Lamberty JM, Thorp TAS, Dwyer JO'. Chronic pain as perceived by older people: a qualitative study. Age Ageing. 2005;34(5):462-6. https://doi.org/10.1093/ageing/afi139.

20. Stewart C, Leveille SG, Shmerling RH, Samelson EJ, Bean JF, Schofield P. Management of persistent pain in older adults: the MOBILIZE Boston study. J Am Geriatr Soc. 2012;60(11):2081-6. https://doi.org/10.1111/j.1532-5415.2 012.04197.x

21. Landi F, onder G, Cesari M, Gambassi G, Steel K, Russo A, et al. Pain management in frail, community-living elderly patients. Arch Intern Med 2001;161(22):2721-4. https://doi.org/10.1001/archinte.161.22.2721.

22. Davis GC, Hiemenz ML, White TL. Barriers to managing chronic pain of older adults with arthritis. J Nurs Scholarsh. 2002;34(2):121-6. https://doi.org/1 0.1111/j.1547-5069.2002.00121.x

23. Pahor M, Guralnik JM, Wan JY, Ferrucci L, Penninx BW, Lyles A, et al. Lower body osteoarticular pain and dose of analgesic medications in older disabled women: the Women's Health and aging study. Am J Public Health. 1999;89(6):930-4. https://doi.org/10.2105/AJPH.89.6.930.

24. Campbell C, Edwards RR. Ethnic differences in pain and pain management. Pain Manag. 2012;2(3):219-30. https://doi.org/10.2217/pmt.12.7.

25. Statistics, C.N.B.o. China statistical yearbook: National Bureau of Statistics of China; 2016.

26. Xue $\mathrm{G}$, et al. The survey of rural elderly with chronic pain among border regions of four provinces: Hunan, Hubei, Chongqing, and Guizhou. Chin J Gerontol. 2012;32(17):3744-6.

27. Wang $Y, X u J$, Song $H$. Prevalence and risk factors of chronic pain in the elderly inpatients. Health Vocation Educ. 2017;35(5):139-41.

28. Si H, Wang C, Jin Y, Tian X, Qiao X, Liu N, et al. Prevalence, factors, and Health impacts of chronic Pain among community-dwelling older adults in China. Pain Manag Nurs. 2019;20(4):365-72. https://doi.org/10.1016/j.pmn.2 019.01.006.

29. Gorstein, J., et al., Indicators and methods for cross-sectional surveys of vitamin and mineral status of populations. 2007.

30. Mccarthy $L H$, et al. Chronic Pain and obesity in elderly people: results from the Einstein aging study. J Am Geriatr Soc. 2008;57(1):115-9. https://doi. org/10.1111/j.1532-5415.2008.02089.x.

31. Cleeland CS, Ryan KM. Pain assessment: global use of the brief Pain inventory. Ann Acad Med Singap. 1994;23(2):129-38.

32. Keller S, Bann CM, Dodd SL, Schein J, Mendoza TR, Cleeland CS. Validity of the brief pain inventory for use in documenting the outcomes of patients with noncancer pain. Clin J Pain. 2004;20(5):309-18. https://doi.org/10.1097/ 00002508-200409000-00005.

33. Gjeilo KH, Stenseth R, Wahba A, Lydersen S, Klepstad P. Validation of the brief Pain inventory in patients six months after cardiac surgery. J Pain Symptom Manage. 2007;34(6):648-56. https://doi.org/10.1016/j.jpainsymma n.2007.01.010.
34. Wang C, et al. Chronic musculoskeletal pain, self-reported health and quality of life among older populations in South Africa and Uganda. Int J Environ Res Public Health. 2018;15(12). https://doi.org/10.3390/ijerph1 5122806.

35. Brooks PM. Issues with chronic musculoskeletal pain. Rheumatology. 2005; 44(7):831-3. https://doi.org/10.1093/rheumatology/keh648.

36. Satghare $P$, et al. Prevalence and correlates of Pain in people aged 60 years and above in Singapore: results from the WiSE study. Pain Res Manag. 2016; 2016:7852397.

37. Breivik H, Collett B, Ventafridda V, Cohen R, Gallacher D. Survey of chronic pain in Europe: prevalence, impact on daily life, and treatment. Eur J Pain. 2006;10(4):287-333. https://doi.org/10.1016/j.ejpain.2005.06.009.

38. Tsang A, von Korff M, Lee S, Alonso J, Karam E, Angermeyer MC, et al. Common chronic pain conditions in developed and developing countries: gender and age differences and comorbidity with depression-anxiety disorders. J Pain. 2008;9(10):883-91. https://doi.org/10.1016/j.jpain.2008.05. 005.

39. Deeny MC, al Hamdan E, Ross EL, Edwards RR, Huang CC, Jamison RN. Chronic Pain, comorbid medical conditions, and associated risk factors in Kuwait: gender and nationality differences. Pain Med. 2015;16(11):2204-11. https://doi.org/10.1111/pme.12840.

40. Green CR, Hart-Johnson T. The association between race and neighborhood socioeconomic status in younger black and White adults with chronic pain. J Pain. 2012;13(2):176-86. https://doi.org/10.1016/j.jpain.2011.10.008.

41. Won $A B$, et al. Persistent nonmalignant pain and analgesic prescribing patterns in elderly nursing home residents: (See editorial comments by Dr. Debra Weiner on pp 1020-1022). J Am Geriatr Soc. 2004;52: 867-74.

42. Carmaciu C, lliffe S, Kharicha K, Harari D, Swift C, Gillmann G, et al. Health risk appraisal in older people 3: prevalence, impact, and context of pain and their implications for GPs. Br J Gen Pract. 2007;57(541):630-5.

43. Janevic MR, McLaughlin SJ, Heapy AA, Thacker C, Piette JD. Racial and socioeconomic disparities in disabling chronic pain: findings from the health and retirement study. J Pain. 2017;18(12):-1467. https://doi.org/10.101 6/j.jpain.2017.07.005.

44. Ikeda T, Sugiyama K, Aida J, Tsuboya T, Watabiki N, Kondo K, et al. Socioeconomic inequalities in low back pain among older people: the JAGES cross-sectional study. Int J Equity Health. 2019;18(1). https://doi.org/1 0.1186/s12939-019-0918-1.

45. Maly A, Vallerand $\mathrm{AH}$. Neighborhood, socioeconomic, and racial influence on chronic Pain. Pain Manag Nurs. 2018;19(1):14-22. https://doi.org/10.1016/ j.pmn.2017.11.004

46. Siciliani L, Verzulli R. Waiting times and socioeconomic status among elderly Europeans: evidence from SHARE. Health Econ. 2009;18(11):1295-306. https://doi.org/10.1002/hec.1429.

47. Feldman $\mathrm{CH}$, Dong $\mathrm{Y}$, Katz JN, Donnell-Fink LA, Losina E. Association between socioeconomic status and pain, function and pain catastrophizing at presentation for total knee arthroplasty. BMC Musculoskelet Disord. 2015;16(1):18. https://doi.org/10.1186/s12891-0150475-8

48. Liguo MA. Analysis of regional balance in elderly Health status and Health services utilization and its change in China: Anhui Medical University; 2012

49. Ye Z, Wu J-j, Yang L. Hospitalization expense of patients with rheumatoid arthritis from urban area in China and its influential factors. Chin Pharm. 2013:024(002):100-2.

50. Baek SR, Lim JY, Lim JY, Park JH, Lee JJ, Lee SB, et al. Prevalence of musculoskeletal pain in an elderly Korean population: results from the Korean Longitudinal Study on Health and Aging (KLoSHA). Arch Gerontol Geriatr. 2010;51(3):-e51. https://doi.org/10.1016/j.archger.2 009.11 .011

51. Catala $\mathrm{E}$, et al. Prevalence of pain in the Spanish population: telephone survey in 5000 homes. Eur J Pain. 2002;6(2):133-40. https://doi.org/10.1053/ eujp.2001.0310.

52. Parsons S, Breen A, Foster N, Letley L, Pincus T, Vogel S, et al. Prevalence and comparative troublesomeness by age of musculoskeletal pain in different body locations. Fam Pract. 2007:24(4):308-16. https://doi.org/10.1 093/fampra/cmm027.

53. Haack M, Scott-Sutherland J, Santangelo G, Simpson NS, Sethna N, Mullington JM. Pain sensitivity and modulation in primary insomnia. Eur J Pain. 2012;16(4):522-33. https://doi.org/10.1016/j.ejpain.2011.07. 007. 
54. Larsson C, Ekvall Hansson E, Sundquist K, Jakobsson U. Impact of pain characteristics and fear-avoidance beliefs on physical activity levels among older adults with chronic pain: a population-based, longitudinal study. BMC Geriatr. 2016;16(1):50. https://doi.org/10.1186/s12877-016-0224-3.

55. Liberman O, Freud T, Peleg R, Keren A, Press Y. Chronic pain and geriatric syndromes in community-dwelling patients aged $\geq 65$ years. J Pain Res. 2018;11:1171-80. https://doi.org/10.2147/JPR.S160847.

\section{Publisher's Note}

Springer Nature remains neutral with regard to jurisdictional claims in published maps and institutional affiliations.

Ready to submit your research? Choose BMC and benefit from:

- fast, convenient online submission

- thorough peer review by experienced researchers in your field

- rapid publication on acceptance

- support for research data, including large and complex data types

- gold Open Access which fosters wider collaboration and increased citations

- maximum visibility for your research: over $100 \mathrm{M}$ website views per year

At $\mathrm{BMC}$, research is always in progress.

Learn more biomedcentral.com/submissions 